\title{
Article
}

\section{But why does what works work? A response to Fifer, Henschen, Gould, and Ravizza, 2008}

\author{
Martindale, A. and Collins, D. \\ Available at http://clok.uclan.ac.uk/12229/ \\ Martindale, A. and Collins, D. ORCID: 0000-0002-7601-0454 (2010) But why \\ does what works work? A response to Fifer, Henschen, Gould, and Ravizza, \\ 2008. The Sport Psychologist, 24 (1). pp. 113-116. ISSN 0888-4781
}

It is advisable to refer to the publisher's version if you intend to cite from the work.

For more information about UCLan's research in this area go to http://www.uclan.ac.uk/researchgroups/ and search for < name of research Group>.

For information about Research generally at UCLan please go to http://www.uclan.ac.uk/research/

All outputs in CLoK are protected by Intellectual Property Rights law, including Copyright law. Copyright, IPR and Moral Rights for the works on this site are retained by the individual authors and/or other copyright owners. Terms and conditions for use of this material are defined in the policies page.

\section{CLoK}

Central Lancashire online Knowledge www.clok.uclan.ac.uk

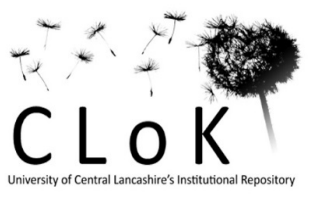


This is a manuscript, as accepted for publication, of an article published by Human Kinetics in The Sport Psychologist in March 2010, available online:

http://journals.humankinetics.com/tsp-backissues/TSPVolume24Issue1March/ButWhyDoesWhatWorksWorkAResponsetoFiferHensche nGouldandRavizza2008

\section{PLEASE REFER TO THE PUBLISHED VERSION FOR CITING PURPOSES}

But Why Does What Works Work? A Response to Fifer, Henschen, Gould, and Ravizza, 2008

Amanda Martindale ${ }^{1}$ and Dave Collins ${ }^{2}$

${ }^{1}$ Dept. of Physical Education, Sport, and Leisure Studies, The University of Edinburgh, Edinburgh EH8 8AQ, Scotland, United Kingdom.

${ }^{2}$ School of Sport, Tourism, and the Outdoors, University of Central Lancashire, Preston, Lancashire, PR1 2HE, United Kingdom. 


\begin{abstract}
The article "What works when working with athletes" by Fifer, Henschen, Gould, and Ravizza (2008) offers an interesting array of information and insights used by three highly experienced applied sport psychology consultants. This response article, however, contends that it may be possible to glean a further, and crucial, level of understanding by exploring the metacognition behind the selection of such courses of action. This may be provided through applied cognitive task analysis (ACTA) techniques to access the cognitive mechanisms underpinning professional practice. A suggested research direction is to use ACTA techniques such as in-depth interviews and cognitive mapping with highly experienced applied sport psychology consultants. Specifically, these techniques would enable readers to access judgments and decisions, attentional demands, critical cues and patterns, and problem solving strategies (Gore \& McAndrew, 2009). This level of understanding may help to establish how these cognitive processes impact on the support provided to clients, and in turn, assist in developing more conceptually rigorous training methods.
\end{abstract}


But Why Does What Works Work? A Response to Fifer, Henschen, Gould, and Ravizza, 2008

Fifer, Henschen, Gould, and Ravizza (2008) offer an interesting array of information and insights used by three highly experienced applied sport psychology consultants in their article "What works when working with athletes". In this regard, it offers a valuable contribution to the professional practice literature. The authors state that, "a highly effective method for disseminating knowledge is to observe the most experienced individuals" (p. 356) and certainly at a fundamental level this is true. It is our contention, however, that it may be possible to glean a further, and crucial, level of understanding by exploring the metacognition behind the selection of such courses of action. In other words, by exploring "why does what works work?" we may be able to gain insight into how practitioners arrived at their stances, came to their decisions, weighed and discarded alternatives, and reached their eventual suggested directions. Without this information, it is difficult for readers to accurately evaluate the applicability of the advice proffered; for example "can I do this?" and "would I do this?" Such questions are dependent on a deeper understanding of the rationale and philosophy behind the action (Poczwardowski, Sherman, \& Ravizza, 2004).

Indeed, Schön's (1991) pioneering work on how professionals think in action refers to a process called 'framing' by which we set the boundaries of our attention and impose a coherence on the situation (e.g., to frame the context). As such, it is likely that optimum transfer from expert to less-expert will involve a reframing or reconceptualization of the problematic situation, "that we may organize and clarify both the ends to be achieved and the possible means of achieving them" (p. 41). This central role for "thinking in action" is sometimes neglected by practitioners in their application of Schön's work, within reflective practice frameworks for example. 
Interestingly, our contention that "why practice is undertaken" is as crucial as "what practice is undertaken" is supported by many of the sources cited by Fifer et al., (2008) in their own paper. In presenting a model for teacher development, for example, Yopp and Guillame (1999) state the importance of students understanding the reasoning of the experienced teacher's decision making:

"After the lesson, the demonstration teacher discusses with the credential students the lesson both in terms of the reasons for conducting that particular lesson with the children and in terms of the "on the spot" decisions that were made during the actual lesson" (p. 8).

In similar fashion, when espousing their model of "cognitive apprenticeship", Collins, Brown, and Holum (1991) observe:

Too little attention is paid to the reasoning and strategies that experts employ when they acquire knowledge or put it to work to solve complex or real-life tasks. . . In cognitive apprenticeship, one needs to deliberately bring the thinking to the surface, to make it visible. ... The teacher's thinking must be made visible to the students and the student's thinking must be made visible to the teacher (p. 1-3).

At the risk of this level of metacognition appearing trivial or, worse still, considered to be naval gazing, it is also worth noting that an increasing body of literature related to the importance of considering professional judgment and decision making is apparent both in our field (e.g., Martindale \& Collins, 2005; 2007) and in parallel fields and professions such as counseling psychology (e.g., Hill, 1992), teaching (e.g., Curtner-Smith, 1999), medicine (e.g., Patel \& Ramoni, 1997), coaching (e.g., Abraham, Collins, \& Martindale, 2004), and refereeing (e.g., Mascarenhas, Collins, Mortimer, \& Morris, 2005). This literature may provide a vehicle for stimulating reflection at a meta-cognitive level through the use of 
suggested terminology as currency for discussion (e.g., notions of theoretical orientation, intentions for impact, and issue conceptualization) to name a few such possibilities. During supervision, for instance, a supervisor might share with a trainee how their (supervisor) theoretical orientation influenced a recent case. In addition, methods for representing the cognitive mechanisms underpinning professional practice have been proposed (e.g., concept mapping and brief structured recall) as well as a range of client-based outcome measures that could be used across multiple levels of support (e.g., session impact, the experiencing scale, and client change interviews). Readers are directed toward Martindale and Collins (2005, 2007) for more detail and discussion of these terms, methods, and measures.

Moreover, in a recent article Gore and McAndrew (2009) provide a methodological perspective on accessing expert cognition in a range of fields from weather forecasting to military command and control. In particular, advances in applied cognitive task analysis (ACTA) are explored and training is suggested to, "assist in developing models of the problem space that practitioners face, and highlight how practitioners achieve expertise" (p. 219). In summary, there are considerable arguments for addressing the reasons underpinning expert judgment.

Reflecting our earlier comments, there are numerous 'missed opportunities' to explore the judgment and decision making of the highly experienced practitioners referred to in the Fifer et al. (2008) article. For example, in the 'delivery of information' section (p. 366-368), where the area of program delivery is discussed in relation to 'how', 'when', and 'where', but not 'why' these strategies were adopted. As such, much of the prose offers a description of 'what' the practitioners have found to work rather than 'why' this was the case. Yet, such detail is an essential step to facilitate the transfer of knowledge from their paper to our practice. To unpack one example, consider the use of peer coaching suggested on p. 369 as a strategy where athletes coach one another on their mental games. This may be an effective 
strategy for use in the examples provided (injury rehabilitation and veteran interviews), however, the explanation as to 'why' this is an appropriate strategy in these contexts (and not others) is not discussed. As such, it does not promote a level of insight whereby the novice practitioner might understand that peer coaching is relevant in these contexts, but unlikely to be effective in highly competitive squad situations, for example, where 'peers' may be competing for places in the same team.

Furthermore, the potential benefits of exploring "why what works works" are apparent for all levels of practitioner, not just for novice practitioners who are developing an understanding of intervention selection. For example, established practitioners wishing to engage in meaningful reflection and highly experienced practitioners, who are perhaps monitoring the standards of the profession through evaluation of their own and other's practice, would also stand to benefit from developing models of the 'problem space' that practitioners face. This insight will, in turn, likely be of benefit to clients as practitioners develop a broader conceptualization of their practice, competence, interpersonal and relational issues, and presentation to the public (Hays, 2006).

As such, a suggested research direction is to employ ACTA techniques to access the judgments and decisions, attentional demands, critical cues and patterns, and problem-solving strategies of highly experienced applied sport psychology consultants (Gore \& McAndrew, 2009). Specifically, in-depth interviews and cognitive mapping could be used as complementary knowledge-elicitation and knowledge-representation techniques. Of particular interest is how these cognitive processes are believed to impact on the overall support process. These techniques have the capability to access practitioners' 'declarative' knowledge in addition to the type of 'procedural' information provided by Fifer et al. (2008) and their use is supported by other calls to follow sport psychology consultants longitudinally to record experienced practitioners' histories (e.g., Tod, 2007). This depth of analysis would 
surely provide a further layer of insight into the cognitive components that govern the generation, selection, and implementation of applied sport psychology practices and, therefore, assist in developing more systematic and conceptually rigorous training methods. Indeed, as Smith, Shanteau, and Johnson (2004) state:

Academic research generally and our society particularly have largely neglected the fact that sound judgment and decision making are the crux of many professions. By understanding and communicating what professional decision makers do and how they do it well, we make valuable contributions both to our field and to the professional community at large" (p. 4). 


\section{References}

Abraham, A., Collins, D.J., \& Martindale, R.J.J. (2004). Validation of a coaching schematic through expert coach consensus. Poster presented at the British Psychological Society Annual Conference, Imperial College, London.

Collins, A., Brown, S.J., \& Holum, A. (1991). Cognitive apprenticeship: Making thinking visible. American Education, 3, 1-18.

Curtner-Smith, M.D. (1999). The more things change the more they stay the same:

Influencing teachers' interpretations and delivery of national curriculum physical education. Sport Education and Society, 4, 75-97.

Fifer, A., Henschen, K., Gould, D., \& Ravizza, K. (2008). What works when working with athletes. The Sport Psychologist, 22, 356-377.

Gore, J., \& McAndrew, C. (2009). Accessing expert cognition. The Psychologist, 22, 218 219.

Hays, K.F. (2006). Being fit: the ethics of practice diversification in performance psychology. Professional Psychology, Research and Practice, 37, 223-232.

Hill, C.E. (1992). An overview of four measures developed to test the hill process model: therapist intentions, therapist response modes, client reactions, and client behaviors. Journal of Counseling and Development, 70, 728-739.

Martindale, A., \& Collins, D. (2005). Professional judgment and decision making: The role of intention for impact. The Sport Psychologist, 19, 303-317.

Martindale, A., \& Collins, D. (2007). Enhancing the evaluation of effectiveness with professional judgment and decision making. The Sport Psychologist, 21, 458-474.

Mascarenhas, D.R.D., Collins, D., Mortimer, P., \& Morris, R.L. (2005). A naturalistic approach to training coherent decision-making in rugby union referees. The Sport Psychologist, 18, 2. 
Patel, V.L., \& Ramoni, M.F. (1997). Cognitive models of directional inference in expert medical reasoning. In P.J. Feltovich, K.M. Ford, \& R.R. Hoffman (Eds.), Expertise in context. Cambridge, MA: MIT Press.

Poczwardowski, A., Sherman, C., \& Ravizza, K. (2004). Professional philosophy in the sport psychology service: Building theory on practice. The Sport Psychologist, 18, 445463.

Schön, D. (1991). The reflective practitioner: How professionals think in action. New York: Arena.

Smith, K., Shanteau, J., \& Johnson, P. (2004). Psychological investigations of competence in decision making. Cambridge: AUS.

Tod, D. (2007). The long and winding road: Professional development in sport psychology. The Sport Psychologist, 21, $94-108$.

Yopp, H., \& Guillaume, A.M. (1999). Preparing pre-service teachers for collaboration. Teacher Education Quarterly, 26, 5-19. 